\title{
IOT In BUILDINGS AND OPtIMIZATION Of ENERgY CONSUMPTION
}

\author{
Petr Štěpán ${ }^{1}$, Zita Prostějovská ${ }^{2}$ \\ ${ }^{1}$ VŠEM, Nárožní 2600/9A, Prague 5, 158 00, Czech Republic, E: petr.stepan@mensa.cz, \\ T.: +420792 309999 \\ 2VŠEM, Nárožní 2600/9A, Prague 5, 158 00, Czech Republic, zita.prostejovska@vsem.cz
}

\begin{abstract}
The Internet of Things (IOT) is a discussed issue nowadays. In our environment, we commonly encounter things connected via the Internet. These are a very wide range of things with different purposes. A specific area of loT is buildings. The goal of the article is to show that not only investment but also the right function during the life cycle it is necessary to monitor whether the purpose is still fulfilled.
\end{abstract}

\section{Keywords}

Internet of Things; Operational Costs; Optimization; Life Cycle.

\section{JEL Classification}

L74 Construction

O33 Technological Change: Choices and Consequences

M15 IT Management

DOI: https://doi.org/10.14311/bit.2020.03.03

Editorial information: journal Business \& IT, ISSN 2570-7434, CreativeCommons license (c) (1) published by CTU in Prague, 2020, http://bit.fsv.cvut.cz/ 


\section{Introduction}

IoT (Internet of Things) is in recent years a very frequently used phrase. Today exist an enormous amount of different "internet" devices. Some of them are "actually" connected to the internet, what means it has its own IP address, it is addressable and are remotely accessible [1]. Main feature of the IoT is high impact on the everyday-life of everyone [2]. The Internet of things is primarily used for creating a special data network from sensors which capture required quantities or which do the given action [1]. IoT has a general goal to connect all to the internet and brings enormous changes to the technologies and communication [3]. Different devices are connected via the internet and are able to associate with each other and collect a huge amount of data [3]. The communication sometimes even runs in one direction. Those devices do not have any IP address and therefore it is necessary to build a special data communication network for the Internet of Things [2], [3]. According to the connection of individual devices through the internet without active human participation. The devices may be for example cars, home appliances, wearable accessories or different sensors which exchange information together [2].

The device (the Thing) is, in the view of the Internet of Things, an inanimate object, which contains in itself electronics, software, and sensors, by which it senses a certain quantity [1]. These information are as data transmitted to Cloud in order to provide its subsequent analysis [1], [2]. The Cloud is a remote server where the data is saved. Performing other operations in order to make them available to the end-user is also possible [1],[2],[3]. The data are available to the end-users most often by website or mobile application [1].

In the buildings is a typical example of loT a measurement system of the reading of energy consumption (electricity, water, heat etc.) where every measuring point is fitted by an loT communication module. The IoT communication module sends to the remote module the current energy consumption [1]. The data are processed in the remote module [2]. The data are then made available to the end-user usually by website or mobile application where the end-user may in the case of energy consumption measurement have a look at his own energy consumption [2].

The purpose of loT is the connection of devices, systems and services in order to provide more data which may be translated into information and the information into knowledge, which may be applied [2], [3]. At the same time it is necessary to realize that it all does not end in acquisition of loT. It is also important to analyse data and then evaluate if the system still brings the desired effects. Especially in intelligent buildings which normally use modern technologies, monitoring is necessary. According to [4] the term "intelligent buildings" is used from early $80^{\prime}$ and a definition formulated by the Intelligent Building Institution in Washington as "one which integrates various systems to effectively manage resources in a coordinated mode to maximize: technical performance, investment and operating cost savings, flexibility" [5]. Intelligent buildings integrate and use various systems with the aim to effectively manage resources, consumption, technical performance and operating cost savings [4]. Cost and their high plays a significant role during the whole life cycle of building. The Life Cycle Cost (LCC) analysis gives an approach to determine a whole cost of a building during the whole life cycle [7], [8], like an investment, operational and maintenance costs, and costs of demolition [8].

Nowadays it is crucial due to climate changes and a low carbon economy approach to construct more intelligent use of energy in buildings which will obviously affect the numbers on energy usage and cost savings [5]. It is known that "buildings are the world's biggest energy drain, consuming a third of final global energy output. They also produce around $20 \%$ of all greenhouse gas emissions" [6, p. 5]. Figure 1 shows how a responsible approach can save the amount of operational costs [5]. 


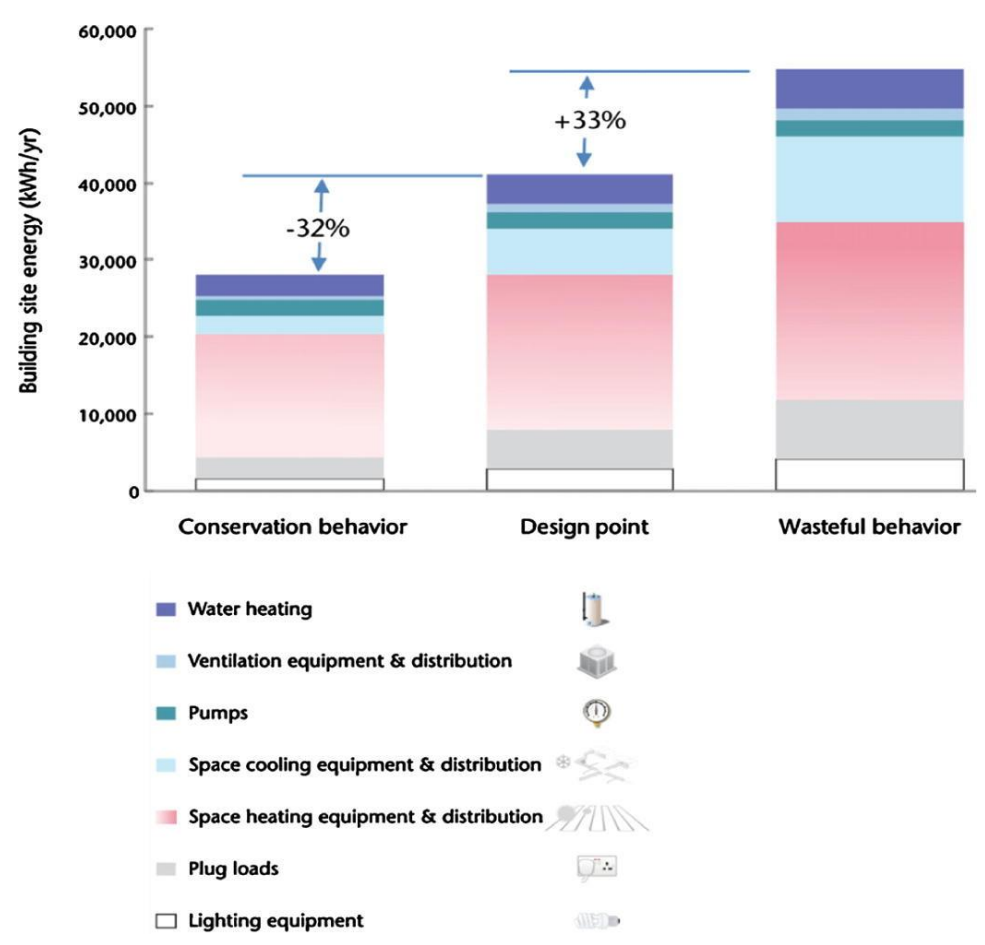

Figure 1: Unwise behavior regarding energy usage doubles the amount of energy as the minimum that can be achieved. (Source: [5])

The investor during the initial decision-making monitors expected operation costs and decides on the acquisition of loT systems that will allow this monitoring (IOT). Monitoring and analysis of operational data is essential throughout ownership. In the article is processed a case study of data usage acquired from the loT system of an existing building in order to minimize energy costs in the building. In the buildings are nowadays used the biggest part of energy in the $\mathrm{EU}$ - to $40 \%$ from the total energy consumption in Europe [6]. Therefore the construction sector and the production of energy efficient appliances make the key part in order to minimize energy consumption in buildings. In practice a huge amount of investment is released into different systems which have an ability to monitor and evaluate the energy consumption. The article shows an example of case study of the possibilities of use of data obtained from devices which enable monitoring of energy consumption in order to optimize energy consumption in office building.

\section{Methodology details}

This case study is focusing on a 21 floor office building. The project was finished in 2012 and received BREEAM Outstanding certification. The building is being used for office rental and as the business case the owner of the building having a fixed lump sum signed with the tenants for the energy consumptions. In 2018 the owner of the building evaluated the total operating costs for 2017 . Then it was found that the cost of energy costs in the building are higher than the contractual payments from tenants. It was found that the actual energy costs per $\mathrm{m}^{2} /$ month reach an average annual value of 3.23 EUR, while the tenant pays $1.25 \mathrm{EUR} / \mathrm{m}^{2} /$ month. With a total leased area of $1,820 \mathrm{~m}^{2}$, the building owner incurred an annual loss of EUR 43,243. The need to seek savings in order to optimize consumption so that contracted payments from tenants to cover their energy consumption was very topical. The aim of the analysis was to find opportunities for energy and cost savings as well as opportunities to improve the quality of the indoor environment (IEQ - Indoor Environment Quality). 
Case study focuses on the consumption of energy not on the materials or construction. The inputs for the study are BMS (Building Management System) data, main electricity meters data, building documentation and the costs paid for consumption.

In the building are different tenants and each of them has individual requirements on IEQ. The system of energy management should be set to the required parameters with goal to mistake reduction and inefficient system switching. BMS collects data from the building environment and sends them to the analytical system Mervis. BMS and Mervis are connected online. Mervis is a cloud service for comprehensive supervision of operating technologies which is responsible for uniform, centralized data processing and their easy availability for both local service and central supervision.

As a part of the analysis were researched in a total of 25 rooms or open spaces in which the proper air temperature is used more than $30 \%$ of the time. Another fact is also that some parts of the building are occupied more than originally expected. In these rooms, the air temperature in the morning is already above the limit and during the day the temperature rises to even higher heat values.

During the consumption analysis the work has been focused on three main points such as the electricity, heating and cooling. The water consumption was analyzed in the energy consumption analysis. Water consumption was examined mainly from the point of view of ensuring the operation of air conditioning. The data obtained from the BMS were compared with the data from invoices for individual media from service delivery providers. The data were examined for the period 01/2017 to $06 / 2018$. Based on the results of the analysis, recommendations were formulated to modify the current settings of the BMS system which should lead to a reduction in total consumption and thus costs and at the same time contribute to a better IEQ of individual tenants.

\section{Results details}

The results received by data analysis are divided according to the medium into three main groups electricity, heating/cooling and water supply. In addition to these three basic groups, IEQ data were analyzed as well.

\section{Electricity}

The building has a built local distribution system (LDS) which is operated by energy suppliers. For the owner of the building this means that it is not necessary to calculate all costs from the transformer station but each customer has his own point of consumption at the low voltage (LV) level.

With the current energy supplier, the price of power electricity is being priced individually. In the year 2017 it is for CZK 676 / MWh which is a lower value than the price for ordinary consumers. The total payment consists of two components, namely payments for the supply of electricity and regulated payments (i.e. power consumption, distribution, support for renewable sources, system services and payment to the operator).

During the analysis time was a single tariff set for customers with medium consumption (C02D). In comparison we also focused on whether the current tariff is appropriate and if necessary, recommend a change to a single tariff for high-consumption customers (CO3D). Due to the fact that unit costs for regulated payments for the C02D tariff are higher than for the C03D tariff as shown in Figure 2. 


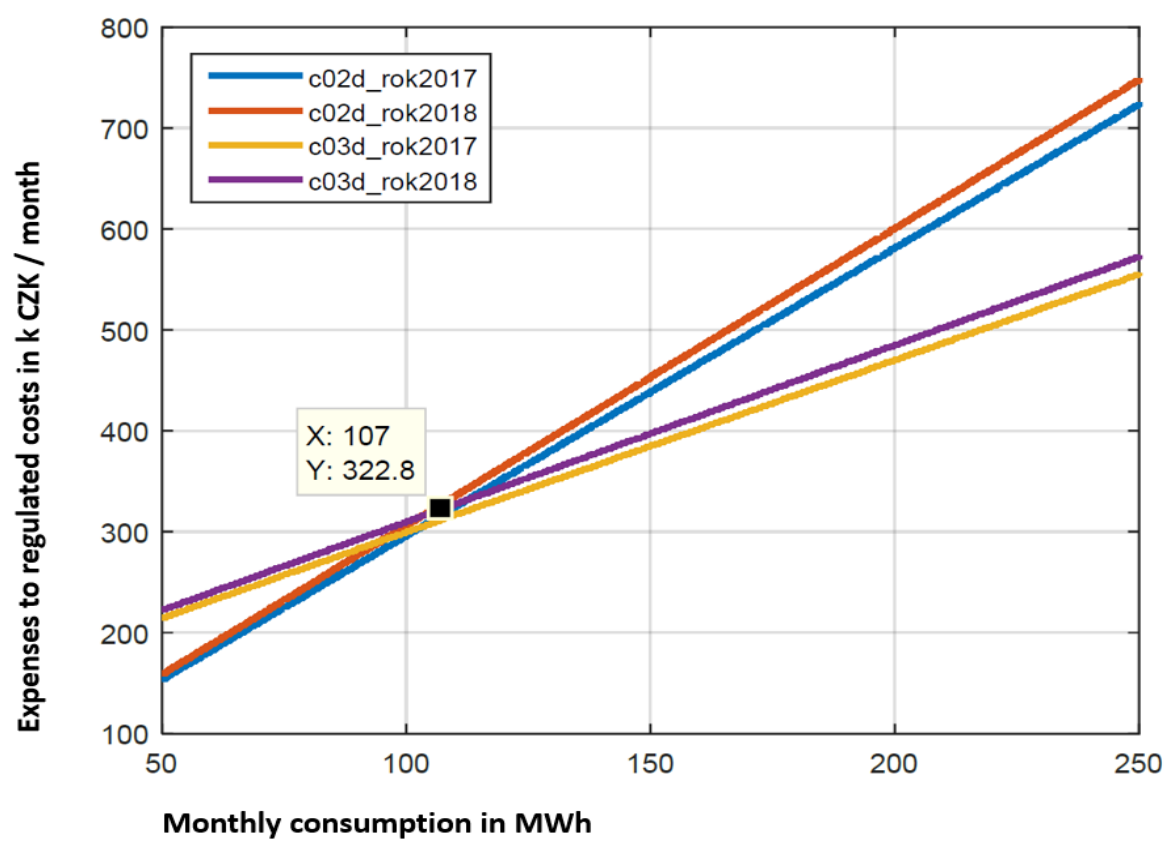

Figure 2: Dependence of monthly costs for regulated payments on consumption for prices from 2017 and 2018 and for tariffs CO2D and CO3D. (Source: authors with the use of [9])

By changing the tariff, significant savings in electricity consumption costs of up to $20 \%$ per month could be achieved with the current consumption of the building. In the event that the $\mathrm{CO} \mathrm{d}$ tariff was agreed in 2017, the average monthly savings on electricity payments will amount to $62 \mathrm{k} \mathrm{CZK}$.

\section{Heating and cooling}

Heating for the building is supplied by the energy contractor in the price common at a given time and location. Invoicing is one-component and due to the terms of the contract, it is not possible to look for any savings here.

In detailed research of heating/cooling the dependence of heat and cold consumption is in individual air conditioning units for each floor on average outside temperature as was analyzed. The results show that the differences are quite high and are determined primarily by the flow temperature for individual air handling units. The flow temperature was not the only factor influencing the consumption, less use of the damper also led to increased heat consumption when increased heat consumption was demonstrated at temperatures around $10^{\circ} \mathrm{C}$.

Figure 3 shows the average heat consumption as a connection to outdoor temperature. The picture shows that the largest heat consumption was on the 3rd, 12th and 20th floors, while the lowest on the 21st floor. 


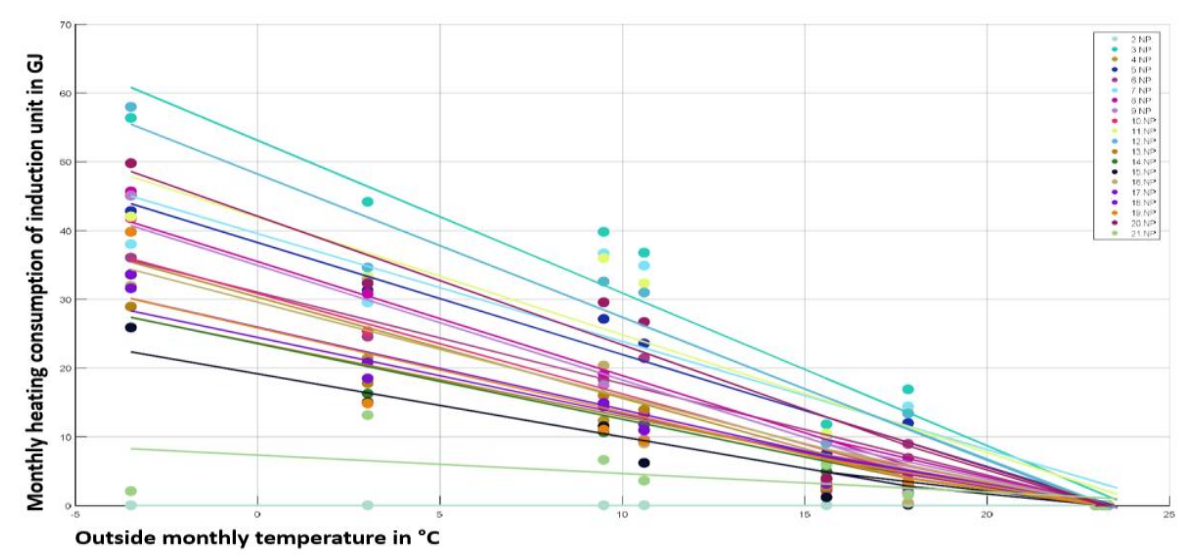

Figure 3: Monthly consumption of heating for every floor in comparison to average outside temperature.

(Source: authors with the use of [9])

In the analysis of cooling consumption as a connection to outdoor temperature in Figure 4 was found that the highest cold consumption at outdoor temperature higher than $23^{\circ} \mathrm{C}$ was achieved in floors 7 th and 19th, the lowest in floors 2nd and 20th.

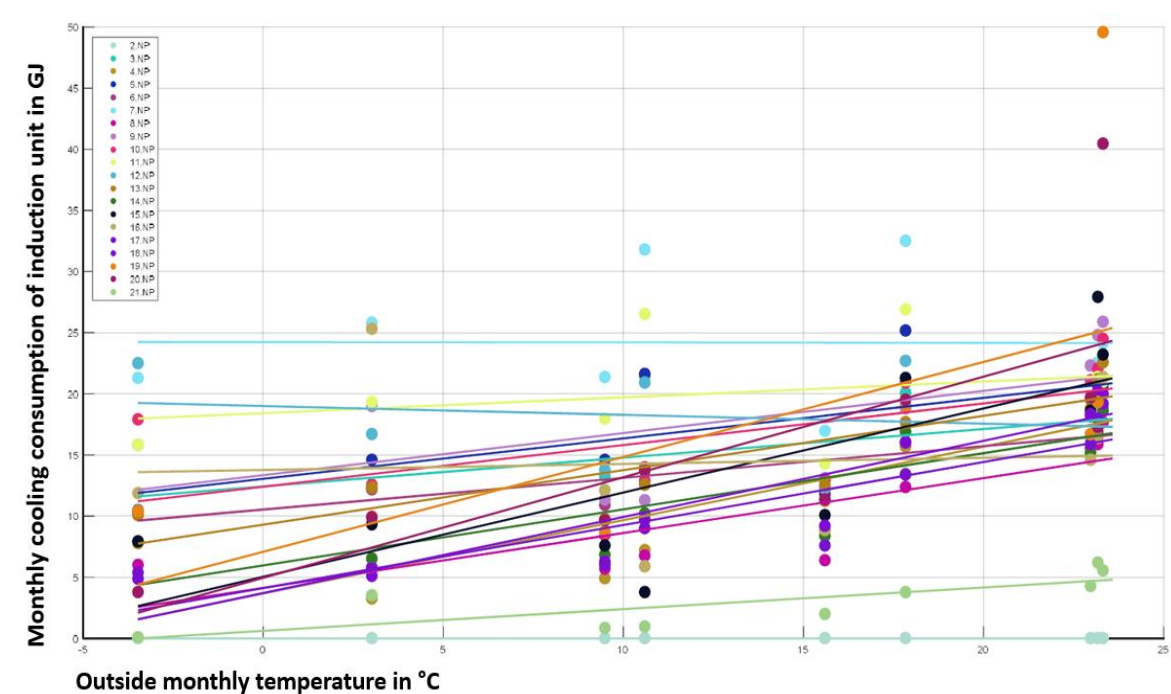

Figure 4: Monthly consumption of cooling for every floor in connection to average outside temperature.

(Source: authors with the use of [9])

\section{Water}

The sources for the analysis of water consumption in the building were invoices from the supplier and service reports. These reports are created on a monthly basis during the maintenance of cooling towers and which also contains a water meter column. In the case of service messages, unfortunately, the records are written in different ways, which introduces big uncertainty into these values. However, from the service reports it seems that the water consumption in the towers are in hundreds of m3 / month.

Invoices data were processed in more detail in the period of years from 2015 to 2017 and compared with the cooling consumption of the building in the same months. For more details see Figure 5. 

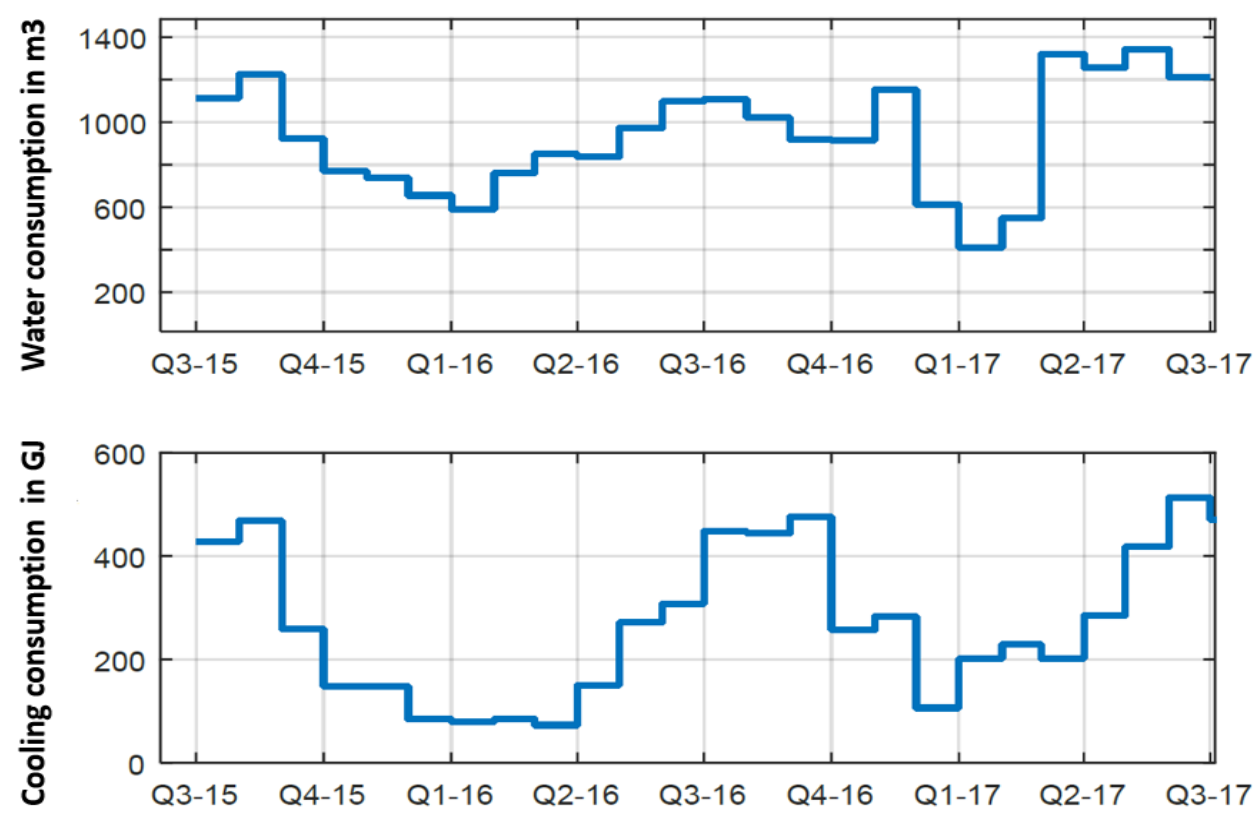

Figure 5: Consumption of water by months in comparison with monthly cooling consumption.

(Source: authors with the use of [9])

In Figure 5 is the significant correlation between individual water consumption and cooling consumption. In addition, it is obvious based on the project documentation, the basic water consumption of the building is assumed permanently approximately $450 \mathrm{~m}^{3} / \mathrm{month}$. This value roughly corresponds to the design documents when $8 \mathrm{I}$ of water per person per day is considered for the offices. It can be concluded that above is this value of the consumption of tower water. This assumption is confirmed by the above values from the service reports.

In addition to the analysis of consumption and costs of basic media, data obtained from the indoor environment management system which is implemented using multi-storey switchboards. This was also analyzed. The analysis of the operation of individual air handling units also showed interesting results. The air handling units are operated without any power attenuation. Air handling units located in the 22 floor operate almost continuously with a frequency converter power higher than $95 \%$. This corresponds very precisely to the monthly consumption. For example, in January 2017, the consumption of the unit marked 1.2, which controls the intensity of air exchange and amounts to 11 MWh. 


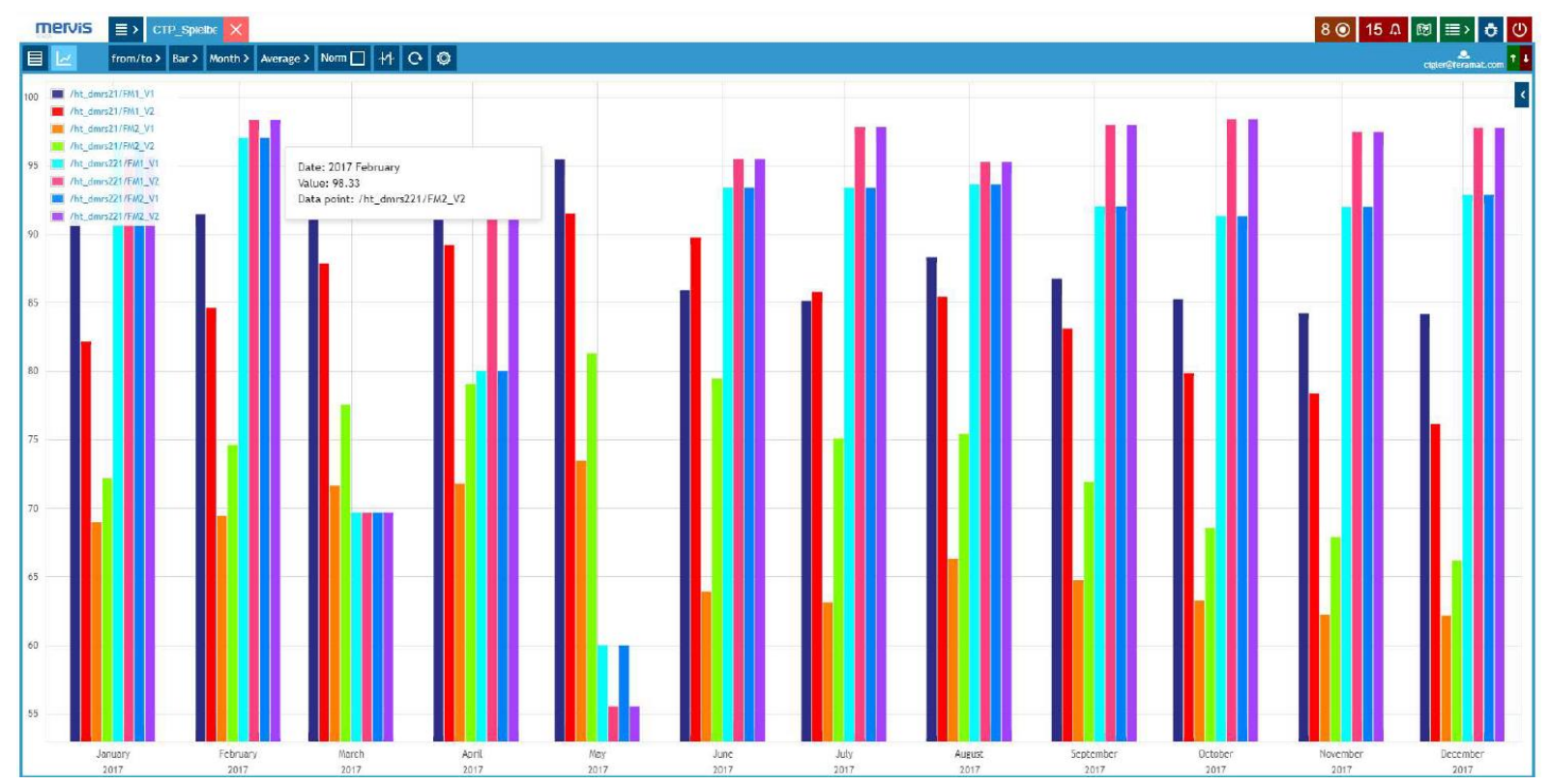

Figure 6: Average percentage of running frequency converters of air handling units. (Source: authors with the use of [9])

Legend: Dmrs221 is a 21st floor switchboard, dmrs21 is a 2PP switchboard. FM1_V1 is a frequency converter for supply to the northern part of the building, FM2_V1 is a frequency converter for extraction from the northern part of the building, FM1_V2 is a frequency converter for supply to the southern part of the building, FM2_V2 is frequency converter for extraction from the southern part of the building

Figure 6 shows the performance of supply and exhaust fans of HVAC units. It is clear from the figure that there is no attenuation in operation and therefore the consumption of this part of the technology is high.

There are no $\mathrm{CO}_{2}$ sensors in many rooms which could be used to detect exhaled air and thus better regulate the operation of air handling units. In the building it is not possible to regulate the air flow to the individual floors so if only one tenant of the range of occupancy of one air handling unit requires comfort 24/7, it is necessary to exchange air in all floors where the air conditioning intervenes.

Based on all performed analyzes, recommendations were formulated which are summarized in Table 1 below.

The recommendations are divided into two basic groups into a group for which it is possible to quantify the amount of savings (marked wc1, wc2 and wc3) and a group for which it was not possible to quantify costs explicitly and only the degree of influence is estimated using qualitative characteristics (marked nc1 - nc9). 
Table 1 Recommendation for savings. (Source: authors with the use of [9])

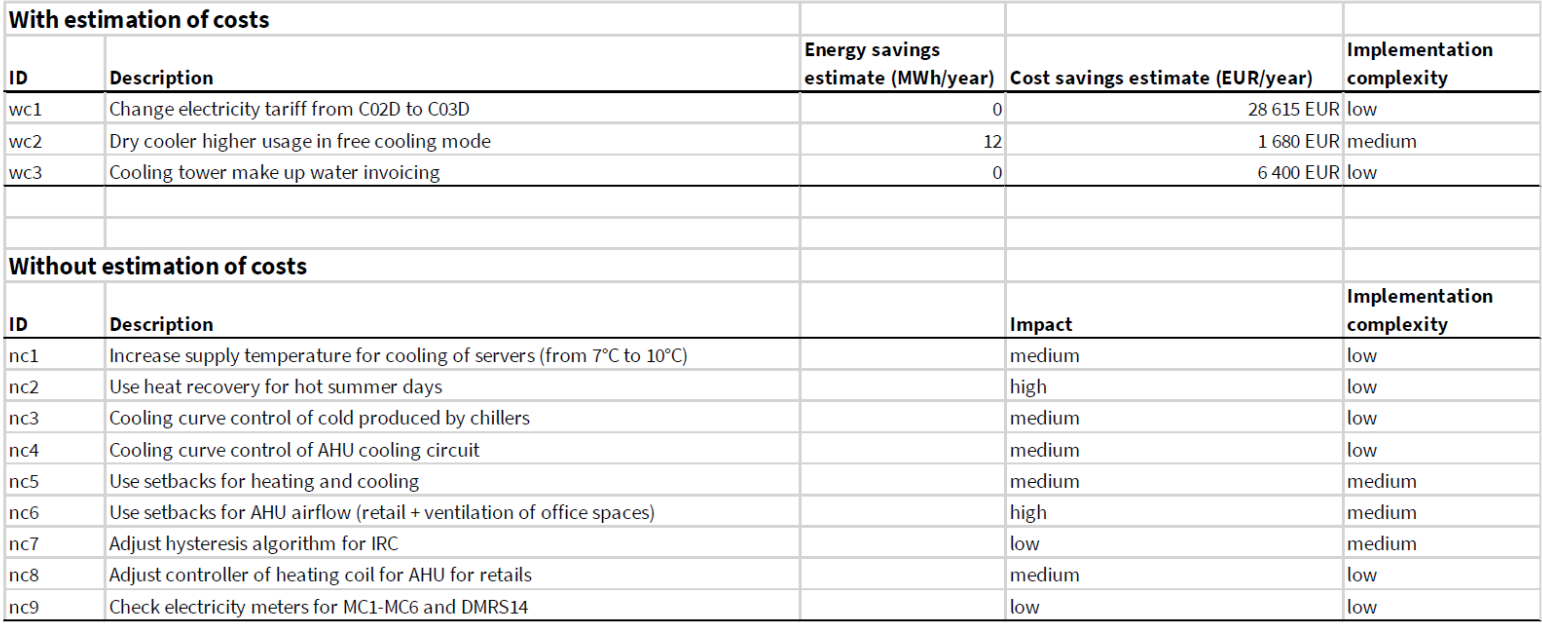

\section{Legend:}

Recommendation nc1: Increase the outlet temperature to the server circuit to at least $10{ }^{\circ} \mathrm{C}$.

Recommendation nc2: Software modification should ensure that rotary regeneration exchanger will be operated continuously except for moments when the outdoor temperature is close to the desired supply air temperature.

Recommendation nc3: Control the preparation of cold in an equity thermal way, as the smaller temperature drop between temperature condenser and evaporator means higher efficiency of cold production. We recommend producing $7{ }^{\circ} \mathrm{C}$ cold only in the moments when the outdoor humidity is high so that there is sufficient power on the cold register for dehumidification of the supply air.

Recommendation nc4: Control the outlet temperature to the air handling unit circuit in an equit thermal manner.

Recommendation nc5: use attenuation to the required room temperatures according to the use of space by tenants.

Recommendation nc6: introduce attenuation in the amount of air supplied to the office space. The project is stated that the flow can be reduced at low outdoor temperatures (below $0^{\circ} \mathrm{C}$ ) up to the $1 / 2$ design flow $50 \mathrm{~m}^{3} / \mathrm{h} /$ person as in project papers.

Recommendation nc7: adjustment of hysteresis of indoor individual controllers for SUMMER and WINTER mode.

Recommendation nc8: modification of the algorithm for VZT8 retail with regard to non-overheating.

Recommendation nc9: check secondary consumables MC1-MC6 and DMR14 as they are used for re-invoicing.

Following the implementation of immediate measures resulting from the actions described in Table 1 above, the actual energy payment was reduced from $3.23 \mathrm{EUR} / \mathrm{m}^{2} / \mathrm{month}$ to $1.39 \mathrm{EUR} / \mathrm{m}^{2} / \mathrm{month}$. Tenants, as mentioned above, have contracted a fixed rate of $1.25 \mathrm{EUR} / \mathrm{m}^{2} / \mathrm{month}$. The proposed measures have significantly reduced the loss resulting from operating costs from the original EUR 43243 to EUR 3057 per year. Although the proposed measures did not achieve the original goal of contracting payments from tenants to cover their energy consumption, they significantly reduced the original loss. Which is $93 \%$ less than the original state. 


\section{Conclusion}

As it is a matter of implementing relatively sophisticated technologies, it is also a matter of understanding and controlling them. However, in general it can be said that the use of modern technologies does not take place at the appropriate level and pace, because it is very difficult to understand them. It is easier not to solve these things and let the current situation flow. Nonetheless, as the strongest motivator is the financial benefit, it can already be stated with certainty that procurement with loT has great potential, especially in the area of office, storage and technologicaloperational will be, which are newly built and use modern technologies.

One of the big challenges in the coming years is that we will learn to use loT for good. However, that takes time.

\section{Acknowledgement details}

This paper was created within the long-term research activities of the main author of the paper. The paper is financed by the University of Economics and Management.

\section{References}

[1] LOM, M., PŘIBYL, O., Sítě pro internet věcí v České republice. TZB-Info. Available online at: https://elektro.tzb-info.cz/informacni-a-telekomunikacni-technologie/16519-site-pro-internet-veci-vceske-republice (accessed 20 July 2019).

[2] ATZORI, L., IERA, A., MORABITO, G. The Internet of Things: A survey. Computer Networks, 2010. doi:10.1016/ j.comnet.2010.05.010.

[3] KHAN, Y. J., YUCE, M. R. Internet of Things (IOT) Systems and Applications. Singapore: Jenny Stanford Publishing, 2019. ISBN 978-0-429-39908-4.

[4] CLEMENTS-CROOME, D. J. What do we mean by intelligent buildings? Automation in construction, 1998, DOI: 10.1016/S0926-5805(97)00018-6.

[5] OSAMA, O. Intelligent building, definitions, factors and evaluation criteria of selection. Alexandria Engineering Journal, 4-2018, pp. 2903-2910. https://doi.org/10.1016/j.aej.2018.07.004.

[6] A handbook on creating dynamic local markets for Energy Efficiency in Buildings. WBCSD, 2016. Available online at: http://docs.wbcsd.org/2016/11/Energy_Efficient_Buildings_Handbook.pdf (accessed 17 July 2020).

[7] NILIMA, N. K., DEEPA, J., RADHIKA, M. Life cycle cost analysis of commercial buildings with energy efficient approach, Perspectives in Science, 8-2016, pp. 452-454. DOI: 10.1016/j.pisc.2016.04.102

[8] SCHNEIDEROVÁ HERALOVÁ, R. Importance of Life Cycle Costing for Construction Projects, Engineering for Rural Development, Proceedings of 17th International Scientific Conference. Jelgava: Latvia University of Agriculture, 2018. p. 1223-1227. ISSN 1691-5976. DOI: 10.22616/ERDev2018.17.N405

[9] Internal information of Feramat Cybernetics s.r.o. 